\title{
DETERMINATION OF PHYSICAL AND CHEMICAL PROPERTIES OF THE MODIFIED SORBENT FROM ASH- AND-SLAG WASTE ACCUMULATED ON ASH DUMPS BY HYDRAULIC ASH REMOVAL
}

\author{
Svyatoslav Andreevich Bushumov and Tatyana Germanovna Korotkova* \\ Kuban State Technological University, 350072, Krasnodar, Russia \\ *E-mail: korotkova1964@mail.ru
}

\begin{abstract}
The physical and chemical properties of the modified sorbent, obtained by calcination at $600^{\circ} \mathrm{C}$ of ash-and-slag waste, accumulated in the ash dump of Novocherkassk SDPP by hydraulic ash removal, were determined: bulk density $0.666 \mathrm{~g} / \mathrm{cm}^{3}$; ash content $-99.5 \%$; and abradability $-8.5 \%$; total pore volume $-0.506 \mathrm{~cm}^{3} / \mathrm{g}$. The granulometric analysis had shown that about $95.2 \%$ of the sorbent fell on a fraction of 0.25 to $0.5 \mathrm{~mm}$. The sorption capacity of the modified sorbent was $0.56 \mathrm{~g} / \mathrm{g}$ concerning petroleum products. A survey of the treatment facilities of the enterprise, specializing in the utilization of industrial waste, including petroleum-contaminated waste and petroleum sludge, was carried out. The degree of wastewater treatment was 94\%. Wastewater treatment from petroleum products was conducted also by the modified sorbent. In this case, the degree of treatment was $97 \%$. It has been concluded that the use of modified sorbent for preliminary treatment of wastewater from petroleum products is more efficient.
\end{abstract}

Keywords: Ash-and-slag Waste, Thermal Power Plant, Hydraulic Ash Removal, Physical and Chemical Properties.

(C) RASĀYAN. All rights reserved

\section{INTRODUCTION}

Hydraulic ash removal is used in thermal power plants using coal as a starting fuel. Ash-and-slag waste is formed by mixing water with captured fly ash and solid slag waste and is sent to the ash dump in the form of pulp. Currently, ash dumps occupy a huge area, having an adverse impact on the environment. Utilization of ash-and-slag waste in Russia amounts to $4-5 \%$. $^{1}$

Conducting quantitative chemical analysis and using the biotesting method, it was determined that the dry ash-and-slag waste after the electric filter and the ash retained by the cyclone and bag filter were at the boundary between the III and IV classes of hazard to the environment (little dangerous). ${ }^{2,3}$ Using the same methods of analysis, it was shown that ash-and-slag waste accumulated on ash dumps by hydraulic ash removal belonged to the $\mathrm{V}$ class of hazard to the environment (practically harmless). ${ }^{4}$ This was explained by the fact that in consequence of the ash-and-slag waste watering and interaction with carbon dioxide in the ash dump sections, the resulting calcium oxide was transformed into less dangerous calcium compounds, such as carbonates, basic and acid salts, and etc. According to the results of the conducted analysis $^{5}$, the ash-and-slag waste at thermal power plants resulting from the coal combustion with acid ash of almost all deposits in Russia is also referred to as the V class of hazard. Ash-and-slag waste is a nonflammable and non-explosive substance, and from an economic viewpoint has a low-cost value, and can be used in various industries.

This work deals with the issue of modification of ash-and-slag waste obtained by hydraulic ash removal, the study of the physical and chemical properties, and testing in the laboratory aiming to treat actual wastewater from petroleum products.

\section{Related Work}

There is a classification of ashes and slags, as well as their chemical and physical characteristics. ${ }^{1}$ Many studies are devoted to determining the parameters of aluminosilicate microspheres (ash microspheres),

Rasayan J. Chem., 13(3), 1619-1626(2020)

http://dx.doi.org/10.31788/RJC.2020.1335454 
RASĀYAN $J$. Chem.

Vol. 13 | No. 3 |1619-1626| July - September | 2020

which are a valuable component of fly ash. ${ }^{6,7}$ Due to their properties, they can be used as additives in composite materials. Some developments are related to their use in road construction. ${ }^{8,9}$ Fly ash is used in the production of cement and concrete ${ }^{10}$, as well as in Portland cement clinker. ${ }^{11}$ The results of studies on the synthesis of zeolites from fly ash have been published in recent years. The sorption-structural parameters of the synthesized zeolites and their cation-exchange properties concerning ammonium, barium, and strontium are determined. ${ }^{12}$ The synthesized zeolites were tested for the treatment of wastewater containing industrial dyes and hazardous ions. ${ }^{13}$ The laboratory study of adsorption properties of ash-andslag waste of Novocherkassk SDPP, obtained during the combustion of the Donetsk culm, has shown the high adsorption capacity and thermal stability in a wide temperature range. The adsorption degree of nitric acid vapor depending on the contact time of ash-and-slag waste with vapors was estimated. With the increase in temperature, sorption properties increased. ${ }^{14}$ Ash-and-slag waste is proposed to be used as a sorbent for the treatment of wastewater contaminated with petroleum products. ${ }^{15}$

Thus, dry fly ash is widely used in various industries. This work is devoted to modification and study of the physical and chemical properties of the sorbent obtained from the watered ash-and-slag waste accumulated on ash dumps.

\section{Methods}

\section{EXPERIMENTAL}

The study of the ash-and-slag waste applicability, selected at the ash dump, was carried out in three stages: drying and calcination of ash-and-slag waste at $600^{\circ} \mathrm{C}$; determination of physical and chemical properties (bulk density, particle size distribution, ash content, total pore volume, abrasion) of the modified sorbent (calcined ash-and-slag waste) and testing of the sorbent in laboratory conditions for the treatment of real wastewater from petroleum products.

Physical and chemical properties of the modified sorbent were determined by the normative documents of Russia (R): environmental regulatory document of the federal level (ERD F); and state industry-standard (SIS). The bulk density of the modified ash-and-slag waste was determined according to SIS R 516412000, granulometric composition - to SIS R 51641-2000, ash content - to ERD F 16.2.2:2.3:3.32-02, the total pore volume - to SIS 17219-71, the durability on abrading - to SIS R 51641-2000, and weight concentration of petroleum products - to ERD F 14.1:2:4.5-95.

\section{Stage-1: Drying and Calcining of Ash-and-slag Waste}

At Novocherkassk SDPP there are three sections of the ash dump. Ash-and-slag waste in the form of the liquid-solid mixture was sampled from the third section (Fig.-1). The ash-and-slag sample was homogenized and placed in a muffle furnace, where it was kept at $110^{\circ} \mathrm{C}$ for 30 minutes to remove free moisture. Dried ash-and-slag sample had a lump shape (Fig.-2).

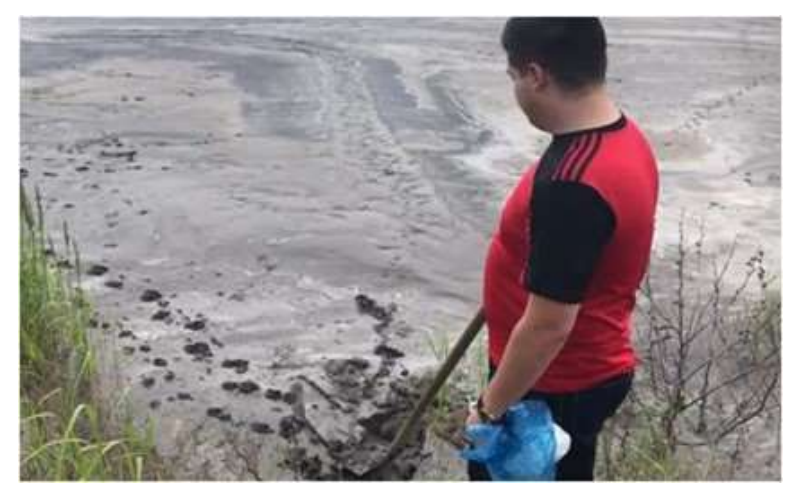

Fig.-1: The Third Section of the Ash Dump at Novocherkassk SDPP

At the next stage, the ash-and-slag waste was modified by calcination at $600^{\circ} \mathrm{C}$ and kept at this temperature for 30 minutes to remove the physicochemically and chemically bound moisture from the pores. This procedure allowed increasing the sorption capacity and obtaining a modified sorbent. After calcination, the 
RASĀYAN J. Chem.

Vol. 13 | No. 3 |1619-1626| July - September | 2020

sorbent became loose and crumbly, containing observed large solid formations that were due to insufficient dehydration of the material (Fig.-3). Thus, to completely remove chemically bound moisture, the sorbent must be kept for at least 40 minutes under specified conditions.

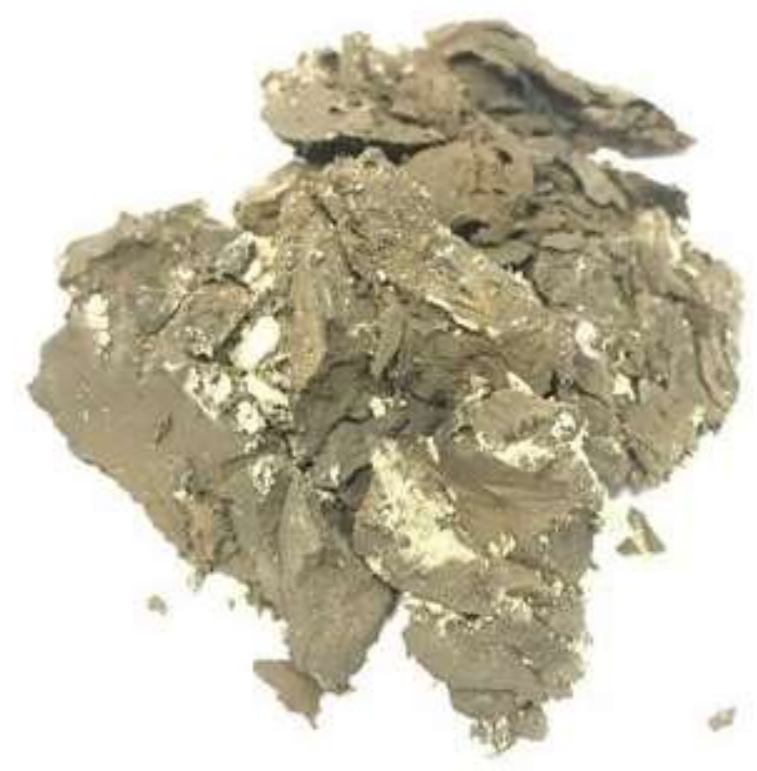

Fig.-2: Ash-and-slag Waste after Drying at $110^{\circ} \mathrm{C}$

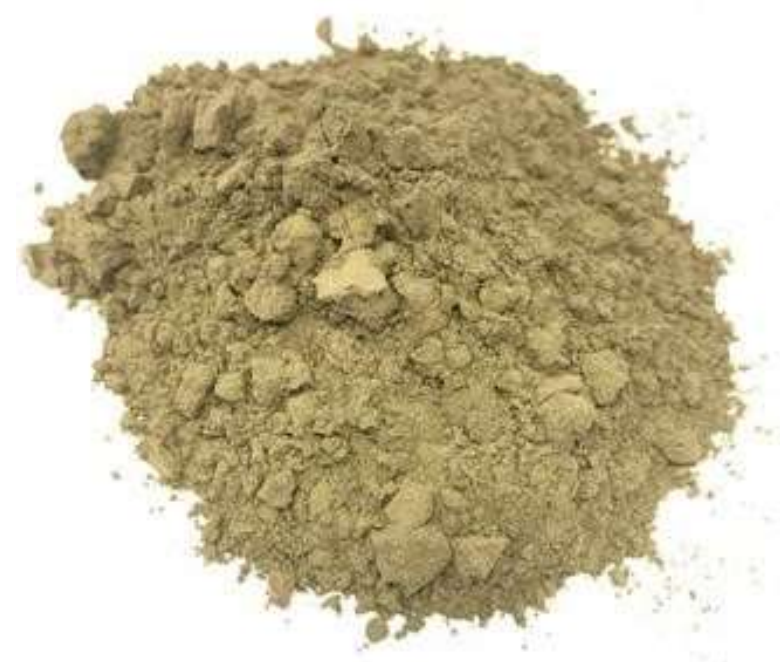

Fig.-3: Modified Sorbent (Calcined)

\section{Stage-2: Determination of Physical and Chemical Properties of the Sorbent Bulk Density Determination}

Bulk density was determined by the following procedure. The modified sorbent was introduced in portions of $20 \mathrm{ml}$ into a pre-weighted cylinder with a volume of $100 \mathrm{~cm}^{3}$ and a height of $240 \mathrm{~mm}$. The cylinder was shaken by tapping the bottom on a wooden stand for 30-40 seconds in an inclined position. The filled cylinder was weighed with precision to the second decimal place. The bulk density of the material, $\rho_{b}$, $\mathrm{g} / \mathrm{cm}^{3}$, was calculated by the formula:

$$
\rho_{b}=\frac{m_{1}-m_{2}}{V}
$$

Where, $m_{1}$ was the weight of the cylinder with the sample weight, $\mathrm{g} ; m_{2}$ was the weight of the empty cylinder, g; $V$ was the volume of sample in the cylinder, $\mathrm{cm}^{3}$. 
RASĀYAN $J$. Chem.

Vol. 13 | No. 3 |1619-1626| July - September | 2020

The final result was taken as the arithmetic mean of two parallel definitions. The permissible absolute discrepancy between the results of the definitions did not exceed $0.01 \mathrm{~g} / \mathrm{cm}^{3}$ with a confidence probability $\mathrm{P}$ equal to 0.95 . The bulk density of the sorbent was $0.666 \mathrm{~g} / \mathrm{cm}^{3}$.

\section{Granulometric Composition Determination}

The granulometric composition was determined by sieving a sample weight of $50 \pm 0.1 \mathrm{~g}$ through standard sieves with the cell size equal to $1.4,1.0,0.5$, and $0.09 \mathrm{~mm}$, employing vibrating screen separators. The vibration frequency amounted to $150 \mathrm{~min}^{-1}$. The selected sample of the material was washed, dried at $110^{\circ} \mathrm{C}$ to a constant weight, then weighed, and sieved manually for 20 minutes. For this, a portion of the material was put to the upper sieve of the set, closed with a lid, and sieved.

After sieving each portion through a set of sieves, the yield of small fractions through each sieve was checked. To do this, each sieve was sharply shaken up over a sheet of white paper. The obtained small fractions that passed through the sieve were collected and transferred to a sieve of a higher caliber. Particles, which stuck in the mesh and thus did not pass through it when shaking, were removed by the needle and considered as particles not passing through the sieve. The rest of the material from each sieve and pallet was separately transferred to clean bowls, pre-dried and brought to a constant weight, and then weighed. The weight fraction of the residue on each sieve $P, \%$, was calculated by the formula:

$$
P=\frac{m_{3}-m_{2}}{m_{1}} \cdot 100
$$

where $m_{1}$ was the sample weight, $\mathrm{g} ; m_{2}$ was the weight of the bowl, $\mathrm{g} ; m_{3}$ was the weight of the bowl with the remainder on the appropriate sieve, $\mathrm{g}$.

According to the results of the analysis, $95.2 \%$ of the sorbent weight falls on particle fraction with a size of 0.25 to $0.5 \mathrm{~mm}$.

\section{Ash Content Determination}

The sample was burned in a muffle furnace at the uniform stepped heating with an increment of $50^{\circ} \mathrm{C}$ up to a temperature of $600^{\circ} \mathrm{C}$, and kept at this temperature to a constant weight. The crucible with a sample was placed in a muffle furnace at room temperature. For 60 minutes, the temperature in the furnace was raised to $450^{\circ} \mathrm{C}$ and maintained for another 60 minutes. The heating was continued to $(600 \pm 5)^{\circ} \mathrm{C}$ in the same furnace, and the sample was kept at this temperature for at least 60 minutes. After calcination, the crucible was removed from the furnace and cooled on a thick metal plate for 10 minutes, and then placed into an exicator without a desiccant. After cooling, the crucible with the ash residue was weighed. Control calculations were performed at $(815 \pm 10)^{\circ} \mathrm{C}$ for several 15 -minute periods until the subsequent weight change did not exceed $1 \mathrm{mg}$. The ash content of sample $A, \%$ by weight, was calculated by the formula:

$$
A=\frac{m_{3}-m_{1}}{m_{2}-m_{1}} \cdot 100
$$

Where $m_{1}$ was the weight of crucible, $\mathrm{g} ; m_{2}$ was the weight of crucible with a sample, $\mathrm{g} ; m_{3}$ was the weight of crucible with ash, $\mathrm{g}$.

$$
A=\frac{4.5843-2.1045}{4.5968-2.1045} \cdot 100=99.5
$$

Ash content of the sample was $99.5 \%$.

\section{Total Pore Volume Determination}

The method to determine pore volume is based on filling pores from 0.5 to $104 \mathrm{~nm}$ in size with water when boiling the sample in water and removing excess water from the surface of the sorbent grains by vacuum filtration under certain conditions. The sample was poured through a funnel into a conical flask, which was filled with $100 \mathrm{~cm}^{3}$ of water and marked its level. The content of the flask was boiled for $(15 \pm 1) \mathrm{min}$, after which cold distilled water was added before the initial volume. The outer surface of the flask was cooled with tap water to room temperature. Next, a device consisting of a Buchner funnel, a receiving flask, and a water jet pump was assembled. A paper filter was placed on the bottom of the Buchner funnel and moistened 
RASĀYAN $J$. Chem.

Vol. 13 | No. 3 |1619-1626| July - September | 2020

with water. Vacuum $(60 \pm 5) \mathrm{mm} \mathrm{Hg}$ was created in the assembled system. During this procedure, it was ensured that the filter was firmly attached to the bottom of the funnel during suction and that the connecting hoses were not bent. The content of the conical flask was drained without loss into the funnel for filtration, and the sample was leveled on the filter surface with a spatula. By turning the tap, one initiated suction, maintaining a vacuum at $(60 \pm 5) \mathrm{mm} \mathrm{Hg}$. Simultaneously, the stopwatch was started. After three minutes, the sample was poured into the weighing vessel, in which the weighing was carried out before the test, for that the flask with the funnel was gently tilted with the tap open, making sure that the water did not fall into the funnel. The grains remaining on the filter were removed with a spatula, transferred to the weighing vessel without loss and closed with a lid. The weighting vessel with the wet sample was weighed to an error of no more $0.01 \mathrm{~g}$ not later than three min after filtration.

The total pore volume $V_{\Sigma}, \mathrm{cm}^{3} / \mathrm{g}$, was calculated by the formula:

$$
V_{\Sigma}=\frac{m_{1}-m}{m \rho}
$$

Where $m$ was the weight of the dry sample, g; $m_{1}$ was the weight of the wet sample, g; $\rho$ was the water density, $\mathrm{g} / \mathrm{cm}^{3}$.

The final result of the test was taken as the arithmetic mean of two parallel definitions. The permissible differences between them at a confidence probability $\mathrm{P}=0.95$ did not exceed $4 \%$ relative to a lower value.

$$
\begin{aligned}
& V_{\Sigma}=\frac{74.9094-50.0029}{50.0029-0.9982}=0.499 \\
& V_{\Sigma}=\frac{75.6202-50.0108}{50.0108 \cdot 0.9982}=0.513
\end{aligned}
$$

The total pore volume was $0.506 \mathrm{~cm}^{3} / \mathrm{g}$.

\section{Determination of Durability on Abrading}

The mechanical durability of the material is characterized by its grindability and abradability. Material samples were thoroughly washed with distilled water, dried at a temperature of $105-110^{\circ} \mathrm{C}$ to a constant weight. Weight was considered constant when the difference of results of two consecutive weightings after drying for $30 \mathrm{~min}$ did not exceed $1 \mathrm{mg}$. Then, the material was sieved separately through sieves No. 2.0 and No. 0.5. Each sample of material weighing $100 \mathrm{~g}$, passed through the sieve No. 2.0 and remained on the sieve No. 0.5, was placed in five glass flasks $250 \mathrm{~cm}^{3}$ in volume with plugs. Each flask was filled with 150 $\mathrm{cm}^{3}$ of distilled water. The flasks were tightly closed with plugs and placed for 24 hours in a shaking apparatus. After shaking, the contents of the flasks were transferred to porcelain bowls and dried at a temperature of $105-110^{\circ} \mathrm{C}$ to a constant weight. Dried sample material was sieved consistently through the sieves No. 0.5 and No. of 0.25 . The weight of the material (in grams), passed through the sieve No. 0.5, but remaining on the sieve No. 0.25 , characterizes the grindability of the material, and is expressed in volume percent of the total weight of the sample material. The weight of the material (in grams), passed through a sieve No. 0.25 , characterizes its abradability and is expressed in volume percent of the total weight of the sample material.

Abradability $B, \%$, was calculated by the formula:

$$
B=\frac{m_{1}}{m} \cdot 100
$$

Where $m$ was the weight of the sample before the test, taken from the sieve after sieving, $\mathrm{g} ; m_{1}$ was the weight of the sample after the test, remaining on the sieve after sieving, g:

$$
B=\frac{42.6971}{502.3187} \cdot 100=8.5
$$

The abradability of the sample was $8.5 \%$.

\section{Sorption Capacity Determination}

The sorption capacity of the sorbent in relation to petroleum products was determined experimentally. Different volumes of solutions with the concentration of petroleum products of $10,000 \mathrm{mg} / \mathrm{dm}^{3}$ were filtered 
RASĀYAN J. Chem.

Vol. 13 | No. 3 |1619-1626| July - September | 2020

through the sorbent weighing $5.0 \mathrm{~g}$. Saturation of the sorbent occurred at a sample volume of about 280 $\mathrm{cm}^{3}$. The content of petroleum products in the filtrate depending on the volume of the filtered model mixture is shown in Fig.-4.

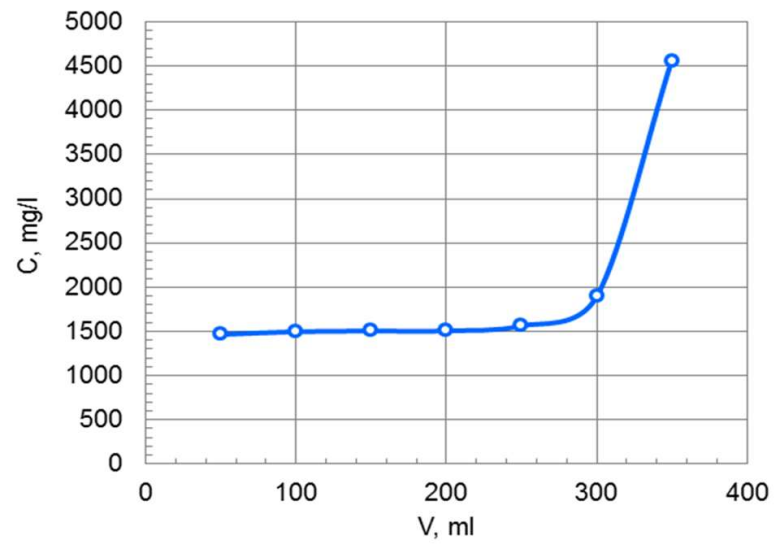

Fig.-4: The Content of Petroleum Products in the Filtrate C, mg/l, Depending on the Volume of the Filtered Model Mixture V, ml.

The sorption capacity of the modified sorbent was $0.56 \mathrm{~g} / \mathrm{g}$ concerning petroleum products.

\section{RESULTS AND DISCUSSION}

Stage-3: Testing the Sorbent in Laboratory Conditions for the Treatment of Real Wastewater From Petroleum Products

To study the effectiveness of treatment with the modified sorbent, a survey of treatment facilities of the LLC Agency "Mercurial Safety" (Krasnodar Region, stanitsa Kholmskaya), which is specializing in the utilization of industrial waste, including petroleum-containing ones, and petroleum sludge, was carried out. A sampling of storm wastewater before and after treatment was carried out. The company uses coal as a sorption material.

The testing of the sorbent was carried out as follows. A sample of the wastewater $1.0 \mathrm{dm}^{3}$ in volume was placed in a reaction vessel and supplemented by a portion of the modified sorbent with a weight of $100 \mathrm{~g}$. The solid-phase extraction was carried out at certain conditions: extraction time was $5 \mathrm{~min}$, while the rotation speed of the magnetic agitator amounted to 200 rpm (Fig.-5).

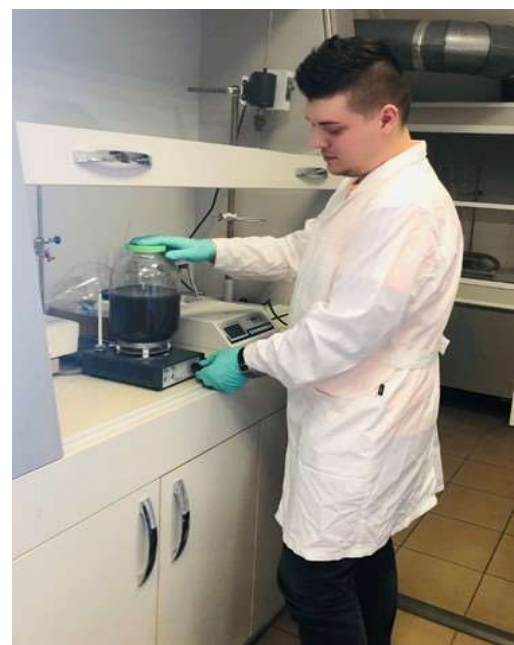

Fig.-5: Treatment of Storm Wastewater by Modified Sorbent: Solid-phase Extraction Process (Author: S.A. Bushumov)

At the end of the extraction process, the system was settled for $5 \mathrm{~min}$. The purified wastewater was decanted quantitatively into a separating funnel for the subsequent determination of the weight content of petroleum 
RASĀYAN $J$. Chem.

Vol. 13 | No. 3 |1619-1626| July - September | 2020

products. Figure- 6 shows the wastewater homogenization process with the carbon tetrachloride $\mathrm{CCl}_{4}$ as the extraction agent. Petroleum products were quantitatively moved into the organic phase during the intense stirring for $4 \mathrm{~min}$. Further, the sample with eluate was settled for 10 min until the complete separation of the liquid phases, and the organic layer was quantitatively poured into a beaker for drying, while the water layer was transferred to the measuring cylinder to determine the exact volume of the extracted sample.

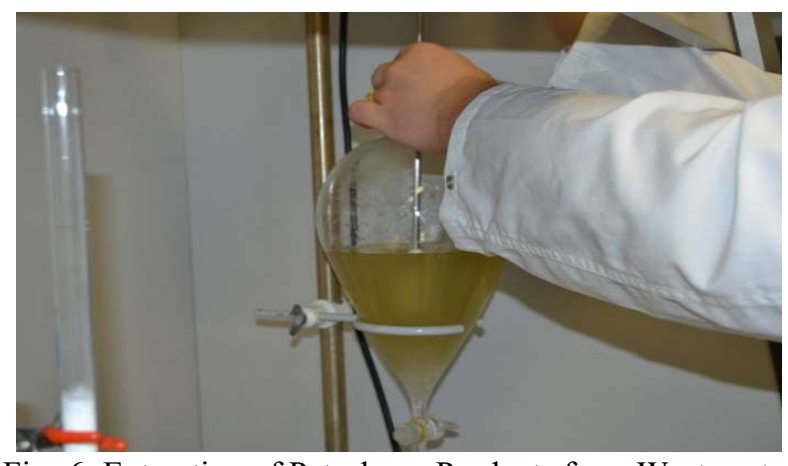

Fig.-6: Extraction of Petroleum Products from Wastewater

Anhydrous sodium sulfate $\mathrm{Na}_{2} \mathrm{SO}_{4}$, previously aged in a drying cabinet at $110^{\circ} \mathrm{C}$ for three hours (Figure 7), was used as a desiccant. The eluate was quantitatively passed through a chromatographic column with activated aluminum oxide to eliminate interfering influences. The subsequent determination of the weight content of petroleum products was detected using the KH-3 concentrator in the IR spectrum of radiation absorbed by $\mathrm{C}-\mathrm{H}$ bonds in hydrocarbons. This experiment made it possible to simulate the conditions of static sorption of storm wastewater generated at the enterprise. The obtained petroleum product content before and after treatment is presented in Table-1. The treatment efficiency with the existing technique and using modified sorbent was 94 and $97 \%$, respectively.

Table-1: Analysis Results of the Weight Content of Petroleum Products in the Studied Wastewater

\begin{tabular}{c|c|c|c|c|c|c}
\hline Tested Water & $K$ & $\begin{array}{c}\text { Sample } \\
\text { Volume, } \\
\mathrm{V}, \mathrm{dm}^{3}\end{array}$ & $\begin{array}{c}\text { Eluate } \\
\text { Volume, } \\
\mathrm{B}, \mathrm{dm}^{3}\end{array}$ & $\begin{array}{c}\text { Indicated } \\
\text { Value, } \\
\mathrm{C}, \mathrm{mg} / \mathrm{dm}^{3}\end{array}$ & $\begin{array}{c}\text { Weight Content of } \\
\text { Petroleum } \\
\text { Products, } \\
\mathrm{X}, \mathrm{mg} / \mathrm{dm}^{3}\end{array}$ & $\begin{array}{c}\text { Expanded } \\
\text { Uncertainty, } \\
\pm \mathrm{U}(\text { at } \mathrm{P}=0.95), \\
\mathrm{mg} / \mathrm{dm}^{3}\end{array}$ \\
\hline Before TF & 5 & 1.00 & 0.024 & 52.7 & 6.32 & 1.64 \\
\hline $\begin{array}{c}\text { After TF } \\
\text { witer treatment }\end{array}$ & - & 1.00 & 0.027 & 13.3 & 0.36 & 0.12 \\
\hline
\end{tabular}

Note: $T F$ means treatment facilities; $K$ means the dilution factor of the eluate.

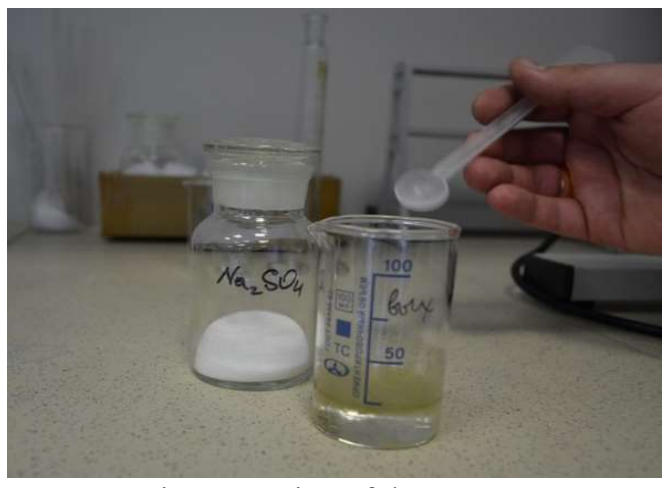

Fig.-7: Drying of the Extract

\section{CONCLUSION}

The modified sorbent was obtained based on the ash-and-slag waste of Novocherkassk SDPP, accumulated in the ash dump by the hydraulic ash removal. Determining the physical and chemical properties of the 
RASĀYAN J. Chem.

Vol. 13 | No. 3 |1619-1626| July - September | 2020

sorbent was as follows: bulk density $-0.666 \mathrm{~g} / \mathrm{cm}^{3}$; ash content $-99.5 \%$; abradability $-8.5 \%$; total pore volume $-0.506 \mathrm{~cm}^{3} / \mathrm{g}$; and sorption capacity in relation to petroleum products $-0.56 \mathrm{~g} / \mathrm{g}$. The particle size analysis had shown that about $95.2 \%$ of the sorbent fell on a fraction of 0.25 to $0.5 \mathrm{~mm}$.

The modified sorbent was tested on real wastewater of the enterprise specializing in the utilization of industrial wastes, including those containing petroleum products and petroleum sludge. At that, coal was used as a sorption material. The laboratory chemical analysis of surface wastewater before and after treatment had shown that the content of petroleum products before treatment was $6.32 \mathrm{mg} / \mathrm{l}$, while after treatment it had reduced to $0.36 \mathrm{mg} / 1$.

Thus, the degree of existing treatment at the enterprise is about to $94 \%$. Wastewater treatment from petroleum products conducted by modified sorbent is about $97 \%$. It is concluded that the use of modified sorbent for preliminary treatment of wastewater from petroleum products is more efficient.

\section{REFERENCES}

1. N.I. Vatin, D.V. Petrosov, A.I. Kalachev and P. Lakhtinen, Civil Engineering Journal, 4, 16(2011), DOI: $10.1088 / 1757-899 X / 365 / 3 / 032040$

2. S.A. Bushumov, T.G. Korotkova, S.Ju. Ksandopulo, N.V. Solonnikova and V.I. Demin, Oriental Journal of Chemistry, 34(1), 276(2018), DOI:10.13005/ojc/340130

3. T.G. Korotkova, S.Ju. Ksandopulo, S.A. Bushumov, S.D. Burlaka and Yu.V. Say, Oriental Journal of Chemistry, 33(1), 186(2017), DOI:10.13005/ojc/330121

4. T.G. Korotkova, S.A. Bushumov, S.Yu. Ksandopulo and N.Yu. Istoshina, International Journal of Mechanical Engineering and Technology, 9(10), 715(2018)

5. É.P. Dik and A.N. Soboleva, Power Technology and Engineering, 40(2), 105(2006), DOI: $10.1007 / \mathrm{s} 10749-006-0029-1$

6. V.S. Drozhzhin, M.Ya. Shpirt, L.D. Danilin, M.D. Kuvaev, I.V. Pikulin, G.A. Potemkin and S.A. Redyushev, Solid Fuel Chemistry, 2, 53(2008)

7. V.E. Samorokov and E.V. Zelinskaya, Bulletin of Irkutsk National Research Technical University, 9(68), 201(2012)

8. A. Hadbaatar, N.A. Mashkin and N.G. Stenina, Procedia Engineering, 150, 1558(2016), DOI: 10.1016/j.proeng.2016.07.111

9. N.P. Sigachev, N.A. Konovalova, V.I. Konnov, P.P. Pankov and N.S. Efimenko, Ecology and Industry of Russia, 19(11), 24(2015)

10. M. Kostović, Underground Mining Engineering, 23, 77(2013)

11. Ch. Hoi King Lam, J.P. Barford and G. McKay, Chemical Engineering Transactions, 21, 757(2010), DOI: $10.3303 /$ CET1021127

12. O.B. Kotova, I.L. Shabalin and E.L. Kotova, Notes of the Mining Institute, 220, 526(2016)

13. N. Koshy and D.N. Singh, Journal of Environmental Chemical Engineering, 4, 1460(2016), DOI:10.1016/j.jece.2016.02.002

14. N.V. Fedorova, Yu.V. Shcheglov and E.M. Antonenko, Sorption and Chromatographic Processes, 12(3), 399(2012).

15. T.I. Shishelova, M.N. Samuseva and B.M. Shenkman, Modern High Technologies, 5, 20(2008)

[RJC-5454/2020] 